This is a post-peer-review, pre-copyedit version of an article published in Environmental Science and Pollution Research. The final authenticated version is available online at:

https://doi.org/10.1007/s11356-019-04921-9.

\title{
Potential control of toxic cyanobacteria blooms with Moroccan seaweed extracts
}

Soukaina El Amrani Zerrifi ${ }^{1}$, Zakaria Tazart ${ }^{1}$, Fatima El Khalloufi 1,2, Brahim Oudra ${ }^{1}$, Alexandre Campos ${ }^{3}$ and Vitor Vasconcelos ${ }^{3,4}$

${ }^{1}$ Laboratory of Biology and Biotechnology of Microorganisms, Faculty of Sciences Semlalia Marrakech, Cadi Ayyad University, Av. Prince My Abdellah P.O. Box 2390, Marrakech 40000, Morocco;

soukainaelamranizerrifi@gmail.com (S.E.A.Z.); zakaria.tazart@gmail.com (Z.T); y Slimane (F.E.K.); oudra@uca.ac.ma (B.O.)

${ }^{2}$ Polydisciplinary Faculty of Khouribga (FPK), Sultan Moulay Slimane University, Morocco.

${ }^{3}$ CIIMAR, Interdisciplinary Centre of Marine and Environmental Research, Terminal de Cruzeiros do Porto de Leixões, Av. General Norton de Matos, s/n, 4450-208 Matosinhos, Portugal; amoclclix@gmail.com

${ }^{4}$ Departament of Biology, Faculty of Sciences, University of Porto, Rua do Campo Alegre, 4169-007 Porto, Portugal

vmvascon@fc.up.pt

\section{Abstract}

Marine macroalgae have acquired a considerable attention as a new promising source of diverse bioactive compounds that can be used in the biocontrol of harmful cyanobacteria blooms (cyanoHABs). In this work, we evaluated the potential algicidal activities of fourteen species of seaweed collected from the coast of Souiria Laqdima, Morocco, extracted with methanol, and screened in solid and liquid medium against the growth of the toxic cyanobacteria Microcystis aeruginosa and the feed microalgae Chlorella sp. After isolation of unicellular M. aeruginosa and Chlorella sp. strains the algicidal activity was tested for the first time by the agar diffusion technique in solid medium and the counting technique in liquid medium. The results in solid medium revealed that the algicidal activity was limited to $M$. aeruginosa. The extract of Bornetia secundiflora showed the highest growth inhibition activity against Microcystis $(27.33 \pm 0.33 \mathrm{~mm})$. Whereas, the extracts of Laminaria digitata, Halopytis incurvus, Ulva lactuca and Sargasum muticum were not showed any zone of inhibition. While, in liquid medium the results indicated that all methanolic extracts of different macroalgae tested have a significant inhibitory effect on $M$. aeruginosa compared to that of the negative control. The maximum inhibition rates of $M$. aeruginosa were revealed by the extracts of Bifurcaria tuberculata, Codium elongatum and B. secundiflora. Moreover, the extracts of $B$. secundiflora recorded the maximum inhibition rate of Chlorella sp. Overall the results highlight the properties of the extracts from macroalgae and their potential use in the control of toxic cyanobacteria species. 
Keywords: CyanoHABs, Microcystis, Algicidal activity, Seaweeds extracts, Biocide effect, Biocontrol.

\section{Introduction}

In recent years, Harmful Algal Blooms (HABs) have been a serious problem for the aquatic ecosystems, the aquaculture industry as well as for the human health (Jeong et al. 2000). Due to the undesirable effects caused by these HABs, extensive research into the topic of the control or mitigation of cyanobacterial blooms has been conducted. Regarding the control of HABs several strategies have been developed which include the use of chemical agents such as copper sulphate (Seder-Colomina et al. 2013). Mechanical control of HABs involves the use of filters, pumps, and barriers (Visser et al. 2005). Biological agents constitute another alternative strategy to the control of HABs. This control can be carried out by microorganisms and herbivorous fishes (silver and bighead carp) (Demeke 2016). Although these methods are useful, they are associated with non negligible deficiency, including nonselective toxicity to many aquatic organisms (Jeong et al. 2000), and high cost (Gao and Xie 2011). Furthermore, some biological methods, such as the introduction of new species in the aquatic environment involves potential biological invasion risks with an imbalance in the trophic chain (Park et al. 2009; Zhu et al. 2010). Thereby the control of cyanobacterial blooms by alternative approachs is of utmost importance. Wherefore, several natural and natural-based compounds from many aquatic and terrestrial plants and seaweeds have been isolated and tested for controlling harmful algae and cyanobacteria (Schrader 2003; Tazart et al. 2018; Tebaa et al. 2018). These compounds involve a variety of bioactive molecules such us rutacridone epoxide from the roots of Ruta graveolens (Meepagala et al. 2005); ethyl 2-methylacetoacetate isolated from an emergent macrophyte Phragmites communis (Li and Hu 2005); N-phényl-2- naphtalène-amine myristate d'isopropyle from the roots of Potamogeton maackianus (Wu et al. 2007); $\alpha$-linolenic acid, oleic acid, and palmitic acid purified from Botryococcus braunii (Chiang et al. 2004).

Seaweeds are amongst the most dominant organisms in marine ecosystems; they have the ability to produce a variety of bioactive compounds with diverse biological activity, namely antibacterial, antifungal and antioxidant (Abdel-Latif et al. 2018; Lezcano et al. 2018; Soliman et al. 2018; Kazir et al. 2019). Moreover, several marine macroalgae have been found to inhibit bloom-forming microalgae (An et al. 2008; Wang et al. 2015, 2018; Zerrifi et al. 2018). Algicidal agents such as, 9-hexadecenoic acid, 2,3-dihydroxypropyl ester purified for the first time from the methanol extract of Ulva prolifera (Sun et al. 2016b); $\alpha$-linolenic acid, oleic acid, and palmitic acid obtained from B. braunii (Chiang et al. 2004); and gossonorol, 7,10-epoxy- 
ar-bisabol-11-ol, glycerol monopalmitate, stigmasterol, 15-hydroxymethyl-2, 6,10, 18, 22, 26,30-heptamethyl-14-methylene-17-hentriacontene, 4 hydroxyphenethyl alcohol, and margaric acid purified from the ethanolic extract of the red alga Gracilaria lemaneiformis (Sun et al. 2017) have been reported.

The most important worldwide freshwater bloom-forming cyanobacteria species are Microcystis species, known as producer of various microcystins congeners (Catherine et al. 2013). To our knowledge very little information is known on the control of Microcystis harmful blooms by using algicidal compounds extracted from seaweeds (Zerrifi etl al. 2018). Our study reports the effects of methanolic extracts of different macroalgae, isolated from Souiria Laqdima, Morocco, on the growth of prokaryotic cells "M. aeruginosa", a cyanobacteria species that commonly form fresh waters Cyano-HABs in Morocco, qualitatively in solid medium by the application of paper disk diffusion as initial screening and quantitatively in liquid medium by cells counting. In addition to the prospecting of possible biocidal action of macroalgae extracts on the growth of prokaryotic cyanobacteria, we tried to see if this effect is selective or not; for this reason, some tests will be carried out on the eukaryotic microalga "Chlorella sp." (Chlorophyceae).

\section{Materials and methods}

\section{Sample Collection.}

According to their ecological interest, availability, accessibility, facilitates harvesting from the coastal area and their potent antifungal or antibacterial activities, 14 seaweeds species belonging to Chlorophyta, Phaeophyta and Rhodophyta were collected from Jorf Lihoudi Sea in Souiria Laqdima, located $30 \mathrm{~km}$ south of Safi, Morocco, during January 2017. All samples were brought to the laboratory in plastic bags containing seawater to prevent evaporation, and then washed with seawater and distilled water to remove epiphytes, sand and other extraneous matter. After identification of each species, the macroalgae were cut into small pieces $<5 \mathrm{~mm}$ x $5 \mathrm{~mm}$ marked and stored at a temperature of $-20^{\circ} \mathrm{C}$ for ulterior lyophilization.

\section{Preparation of algal extracts.}

Macroalgae tissues were subjected to methanol extraction following the method previously described by Sahnouni et al. (2016) with minor modifications. Each $20 \mathrm{~g}$ of lyophilized sample was soaked in $100 \mathrm{ml}$ of methanol at room temperature for 1 day with agitation and filtered through no. 2 filter paper under reduced pressure. This extraction procedure was repeated three times, and the extracts were combined. The combined filtrates 
were concentrated by rotary evaporation at $45-50^{\circ} \mathrm{C}$. The resulting dried extracts were then dissolved in dimethlysulfoxide (DMSO) and kept at $4^{\circ} \mathrm{C}$ until further use.

\section{Microalgae media and growth conditions.}

BG 13 and Z8 media were used as the base for solid and liquid media. The $\mathrm{pH}$ of both media was adjusted to 9.0. Solid media were prepared on a base of BG 13 medium consolidate with $0.4 \%$ of agarose, the medium composition and the agarose was autoclaved separately at $121^{\circ} \mathrm{C}$ for $15 \mathrm{~min}$ and then mixed together after cooling (Shirai et al. 1989). Microalgae growth was performed in a culture chamber with the following conditions: $26 \pm 2^{\circ} \mathrm{C}$ under light intensity of 4000 lx.m ${ }^{-2} \mathrm{~s}^{-1}$, with a light/dark cycle of $15 \mathrm{~h} / 9 \mathrm{~h}$.

\section{Isolation of unicellular M. aeruginosa strain.}

A natural cyanobacterial bloom that consisted of over $95 \%$ of $M$. aeruginosa was collected from the eutrophic reservoir Lalla Takerkoust $\left(31^{\circ} 21^{\prime} 36^{\prime \prime} \mathrm{N} ; 8^{\circ} 7^{\prime} 48^{\prime \prime} \mathrm{W}\right)$, Morocco in October 2015. The morphotypes of $M$. aeruginosa were identified individually using a microscope according to their colonial morphologies. In order to break up the colonies in culture and separate them into single cells, the obtained buoyant cells in the top layer of $M$. aeruginosa complex culture were suspended in sterilized water. This procedure was repeated five times to wash the cells. Afterward, $2 \mathrm{~mL}$ of the washed cells were vigorously shaken by a vortex mixer for 1 to $2 \mathrm{~min}$ and serially diluted 10-fold in sterilized distilled water before plating, poured into BG 13 medium with $0.4 \%$ agarose, allowed to solidify, and incubated for 7 to 10 days (first culture). When the colony formation was observed, the Microcystis cells in the colonies were transferred to fresh agarose medium and incubated again (second culture). The cells in the second culture were inoculated into Z8 medium and cultured for 7 to 14 days (Shirai et al. 1989).

\section{Isolation of Chlorella sp. strains.}

Water sampling was carried out in a basin within the Faculty of Sciences Semlalia (Marrakech) and the sample was concentrated with $30 \mu \mathrm{m}$ plankton net. In order to obtain pure isolates, a series of successive subculturings was carried out on solid Z8 medium. Colonies with a macroscopic appearance similar to Chlorella sp. confirmed under a microscope, were selected and maintained in batch cultures on Z8 liquid medium.

\section{Screening for algicidal activity.}


Algicidal activity assays on solid media.

The potencies of seaweeds methenolic extracts against the two tested species was assessed qualitatively by the application of paper disk diffusion. Sterile filter paper discs, $9 \mathrm{~mm}$ in diameters (Whatman No. 1), were loaded with $20 \mu 1$ of the different extracts and air dried. The crude extracts were dissolved in $0.2 \%$ DMSO because the growth of algae was not influenced at this solvent concentration, as confirmed in a previous study (Kamaya et al. 2003). Discs impregnated with cooper sulphate and DMSO were used as positive and negative controls respectively. The discs were placed on BG13 with $4 \%$ of agarose medium and Z8 medium inoculated respectively with $M$. aeruginosa and Chlorella sp. (inoculum was prepared from a culture of 7 days). The plates thus prepared were stored in a refrigerator at $4{ }^{\circ} \mathrm{C}$ for at least four hours to allow diffusion of the bioactive substances contained in the extracts into the solid medium while arresting the growth of the test microalgae. All the experiments were repeated three times to validate the findings statistically.

\section{Algicidal activity assays on liquid media.}

The algicidal activity in liquid medium of methanolic extracts against the two tested species was performed in polystyrene 6-well macroplates. $10 \mu \mathrm{L}$ of extract were added to $5 \mathrm{~mL}$ of microalgal culture to final concentrations of $0,0.3$ and $0.6 \mathrm{mg} / \mathrm{mL}$, respectively (Those two extract concentrations were shown to be the most affective dose used for microalgae growth control by seaweeds extracts (Sun et al. 2016a)). Equal volumes of DMSO and copper sulphate were used respectively as negative and positive control. In addition, an untreated microalgal culture was used as negative control for achievement of the different calculations necessary for the results treatment. The initial density of M. aeruginosa and Chlorella sp. cultures was adjusted to $3 \times 10^{6}$ cells $/ \mathrm{mL}$ (the exponential growth phase).

\section{Determination of microalgae growth and inhibition rates.}

The effects of different methanolic extracts on the tested microalgae were determined by estimation of growth and inhibition rates. This was done by repeated cells counting using a hemocytometer under a microscope (Sbiyyaa et al. 1998). Inhibition rate (IR inhibition rate \%) was calculated by the following equation (1) :

$$
\operatorname{IR}(\%)=((\mathrm{N} 0-\mathrm{NS}) / \mathrm{N} 0) \times 100
$$


In which N0 and NS (cells $/ \mathrm{mL}$ ) are the cell densities in the control and treatment samples, respectively.

Moreover, growth rate was calculated using the following equation (2) (Xu et al. 2010):

$$
\mu=(\ln N 2-\ln N 1) / \Delta t
$$

where, $\mu$ is the average growth rate; N2 and N1 represent the cell concentrations at the end and at the beginning of the experiment, respectively and $\Delta \mathrm{t}$ indicates the time period of the experiment.

\section{Statistical analysis.}

The experiments were repeated three times $(n=3)$ with each independent assay. Statistical differences between experimental groups and the control were analysed by applying a one-way and two-way ANOVA. Post hoc differences between group means were tested with the Tukey test. Values of P lower than 0.05 were considered significant. Statistical analyses were performed using the computer software Sigma Plot 12.5 for Windows.

\section{Results.}

\section{Isolation of unicellular M. aeruginosa strain.}

After two weeks of incubation time, blue-green colonies had grown in BG 13 media with $0.4 \%$ of agarose. From the $3^{\text {rd }}$ week, these colonies begin to change their colours to white and the cells forming these white colonies lost their ability to develop new colonies in a subsequent culture. In addition, M. aeruginosa strains becomes able to form a mat in the solid medium (figure 1). 


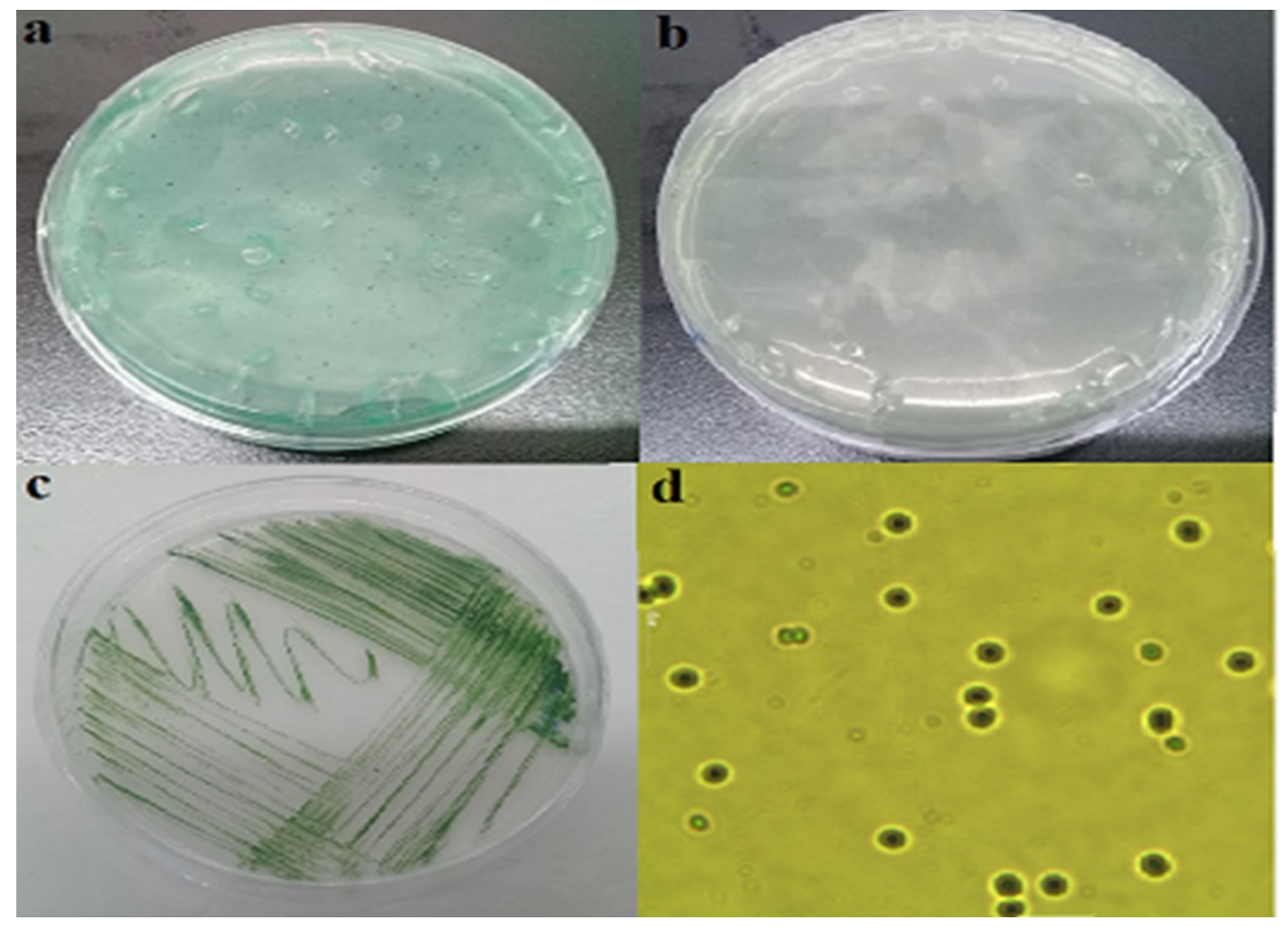

Figure 1. Colonies of $M$. aeruginosa on an agarose $0.4 \%$ plate a) After two weeks of incubation; b) After four weeks of incubation. c) Unicellular M. aeruginosa in BG13 medium with $0.4 \%$ of agarose plate. d) Microscopic observation of unicellular M. aeruginosa isolated (Gr. x 100).

Isolation of Chlorella sp. strain. 
After a series of successive subcultures, the colonies with a macroscopic appearance approaching to Chlorella were observed under a microscope for identification and maintenance in batch culture on Z8 liquid medium. Thereafter, monospecific strain of Chlorella was purified (figure 2).

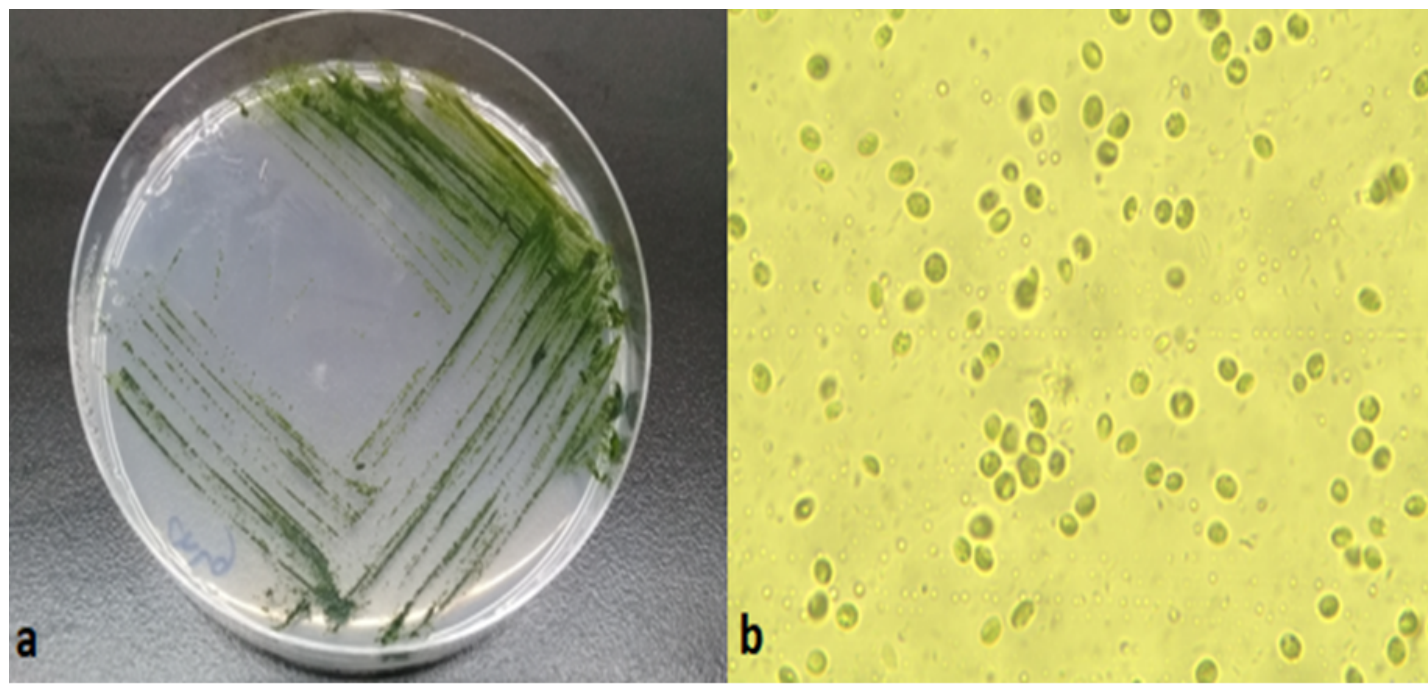

Figure 2. a). Colonies of isolated Chlorella sp. in Z8 medium. b). Microscopic observation of Chlorella sp. isolated (Gr. x 100).

\section{Evaluation of algicidal activity on solid media}

Table 1. Inhibition of microalgae in solid media assays, in the presence of methanolic extracts of Moroccan seaweeds. Diameter $(\mathrm{mm})$ of the area of growth inhibited by the seaweed extracts.

\begin{tabular}{ccc} 
& \multicolumn{2}{c}{ Zone of inhibition (mm) } \\
\hline Treatments & M. aeruginosa & Chlorella $\mathbf{s p}$. \\
\hline Codium elongatum & $14.33 \pm 0.33^{* * *}$ & $0 \pm 0 \mathrm{~ns}$ \\
Laminaria digitata & $0 \pm 0 \mathrm{~ns}$ & $0 \pm 0 \mathrm{~ns}$ \\
Cystoseira ericoides & $16.33 \pm 0.33^{* * *}$ & $0 \pm 0 \mathrm{~ns}$ \\
Bifurcaria tuberculata & $11 \pm 0.00^{* * *}$ & $0 \pm 0 \mathrm{~ns}$ \\
Geledium pulchellum & $16.67 \pm 0.33^{* * *}$ & $0 \pm 0 \mathrm{~ns}$ \\
Laurencia pinnatifida & $17.33 \pm 0.33^{* * *}$ & $0 \pm 0 \mathrm{~ns}$ \\
Cystoseira tamarisafolia & $13.33 \pm 0.33^{* * *}$ & $0 \pm 0 \mathrm{~ns}$ \\
Halopytis incurvus & $0 \pm 0 \mathrm{~ns}$ & $0 \pm 0 \mathrm{~ns}$ \\
Plocamium coccineum & $11 \pm 0^{* * *}$ & $0 \pm 0 \mathrm{~ns}$ \\
Ulva lactuca & $0 \pm 0 \mathrm{~ns}$ & $0 \pm 0 \mathrm{~ns}$ \\
Rhodymenia pseudopalmata & $11.33 \pm 0.33^{* * *}$ & $0 \pm 0 \mathrm{~ns}$
\end{tabular}


Bornetia secundiflora

Enteromorpha intestinalis

Sargassum muticum

Copper sulphate
$27.33 \pm 0.33 * * *$

$11.33 \pm 0.33^{* * *}$

$0 \pm 0 \mathrm{~ns}$

$45.33 \pm 0 * * *$
$0 \pm 0 \mathrm{~ns}$

$0 \pm 0 \mathrm{~ns}$

$0 \pm 0$ ns

$62,67 \pm 0^{* * *}$

DMSO

$0 \pm 0$

$0 \pm 0$

$* * * \mathrm{P}<0.001$ indicate significant differences compared with the negative control. ns mean no significant differences compared with the negative control. Each value representing mean \pm SD of 3 replicates.

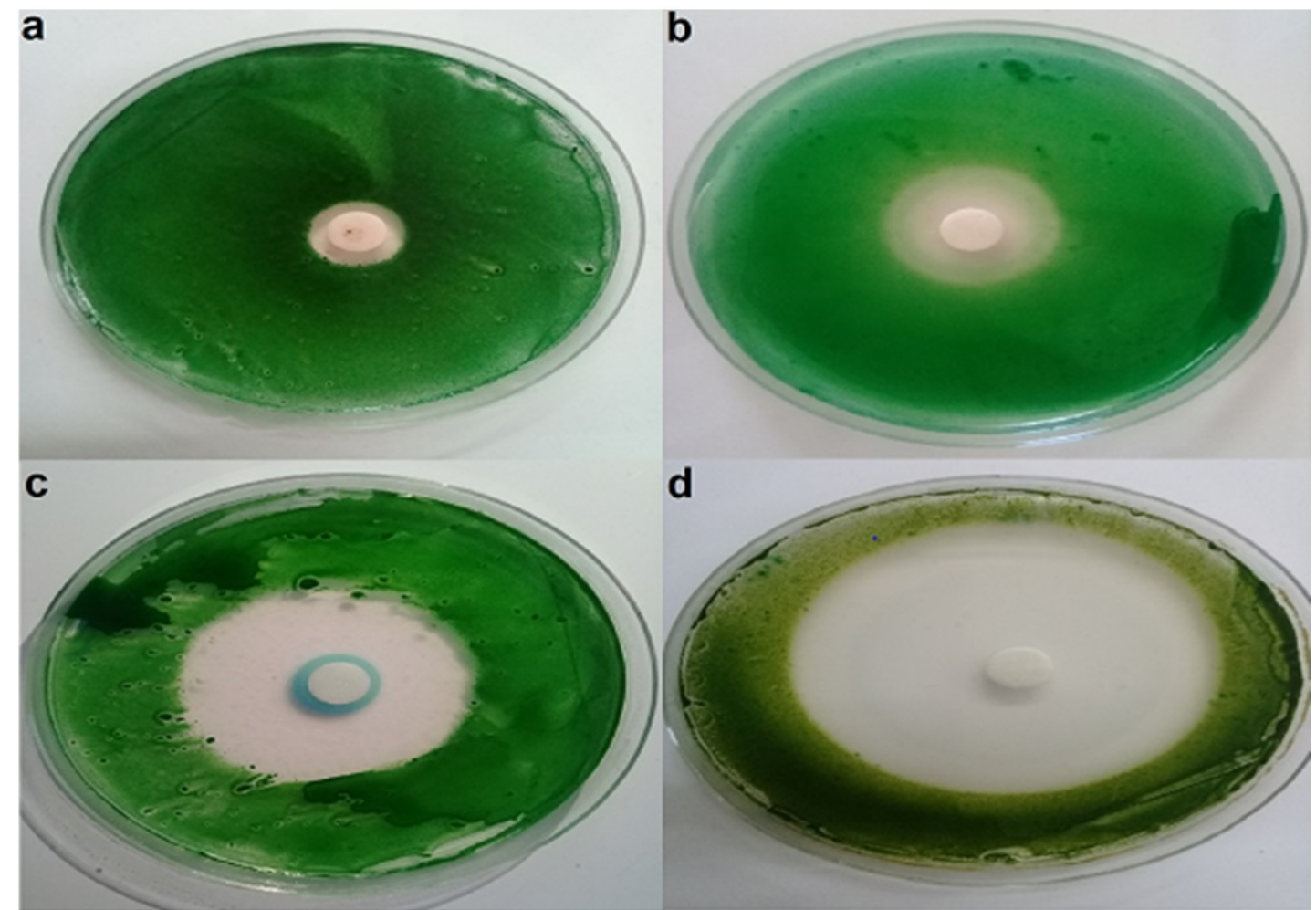

Figure 3. Algicidal activity of methanolic extracts against $M$. aeruginosa a). G. pulchellum b). B. secundiflora. c). copper sulphate d). Copper sulphate against Chlorella sp.

After 7 days of incubation, the measurement of the inhibition zones has been done and the results of algicidal activity in solid medium are summarized in table 1 and figure 3. DMSO and copper sulphate were used as negative and positive control respectively; the negative control (DMSO) never showed algicidal activity while copper sulphate showed strong activity against both tested microalgae (45.33 \pm 0 and $62.67 \pm 0 \mathrm{~mm}$ against $M$. aeruginosa and Chlorella sp. respectively). However, ten extracts out of fourteen from different species of Moroccan seaweeds showed algicidal activity against $M$. aeruginosa. In contrast no extracts showed algicidal activity against Chlorella sp. The most important activity against $M$. aeruginosa (e.g. diameter of growth inhibition higher than $27 \mathrm{~mm}$ ) was observed in the extract 
of the red macroalgae $B$. secundiflora, whereas moderate activity against $M$. aeruginosa was observed with the extracts of L. pinnatifida, G. pulchellum, C. ericoides and Codium elongatum (the diameter of inhibition zone was $17.33 \pm 0.33 \mathrm{~mm}, 16.67 \pm 0.33 \mathrm{~mm}, 16.33 \pm 0.33 \mathrm{~mm}$ and $14.33 \pm 0.33 \mathrm{~mm}$, respectively). The lower inhibitory effect for M. aeruginosa was recorded in the methanolic extracts of B. tuberculata and P. coccineum $(11 \pm 0.00 \mathrm{~mm})$. The extracts of $L$. digitata, H. incurvus, U. lactuca and S. muticum did not reveal any inhibitory activity against the cyanobacterium.

\section{Evaluation of algicidal activity on liquid media}

\section{Inhibitory rates of seaweeds methanolic extracts on microalgae tests}

The inhibition rates of the fourteen macroalgal crude extracts tested at the 2 concentrations $(0.3,0.6 \mathrm{mg} / \mathrm{mL})$ against $M$. aeruginosa and Chlorella sp. growth is shown as the IR (\%) in tables 2 and 3 respectively. Copper sulphate as positive control showed strong inhibition of M. aeruginosa and Chlorella sp., during the entire follow-up period the IR was more than $86 \%$ for both tested concentrations, while DMSO, as negative control, did not show any inhibitory effect on both tested microalgae $(\mathrm{IR}<0.5 \%)$. The results indicate that all methanolic extracts of different macroalgae had a significant inhibitory effect on M. aeruginosa compared to the negative control. At the first day of treatment, the macroalgal extracts of $B$. secundiflora, C. elongatum, E. intestinalis, B. tuberculata and S. muticum showed strong growth inhibition (IR $>50 \%$ for both tested concentrations) on $M$. aeruginosa. The lowest inhibition rate was recorded by the methanolic extract of $C$. tamarisafolia (IR $<32 \%$ for both concentrations used). The IR of $B$. secundiflora extract was a maximum of $80.65 \pm 0.23 \%$ and $73.63 \pm 0.19 \%$ at $0.6 \mathrm{mg} / \mathrm{mL}$ and $0.3 \mathrm{mg} / \mathrm{mL}$ respectively, on the first day; thereafter, it began to decrease gradually but was maintained at more than $21 \%$ all the time. At the end of the experiment, the maximum inhibition rates were revealed by the extracts of $B$. tuberculata, $C$. elongatum and B. secundiflora. The IR reached at a concentration of $0.3 \mathrm{mg} / \mathrm{mL}$ was $24.2 \pm 0.24$ $\%, 22.24 \pm 0.24 \%$ and $21.28 \pm 0.22 \%$ respectively. The higher concentration $(0.6 \mathrm{mg} / \mathrm{mL})$, of $P$. coccineum showed the most important inhibitory effect on M. aeruginosa $(26.57 \pm 0.41 \%)$. Whereas at a concentration of $0.3 \mathrm{mg} / \mathrm{mL}$ the lowest inhibition rates were observed in the extract of the brown seaweeds C. ericoides $(8.25 \pm 0.48 \%)$ and $S$. muticum $(9.95 \pm 0.16 \%)$. This last species showed the lowest effect at $0.6 \mathrm{mg} / \mathrm{mL}$ too $(11.96 \pm 0.02 \%)$. The effects of methanolic macroalgae extracts tested against Chlorella sp. varied according to the macroalgae species from which the extracts were obtained. Firstly, the extract of $R$. pseudopalmata, E. 
intestinalis and S. muticum promotes the growth of Chlorella at the first day of treatment. In the days after an inhibition that does not exceed 3\% begins to appear. In the other hand, $C$. ericoides and $C$. elongatum have the maximum inhibition rate at the first day $(16.64 \pm 2.81 \%$ and $11.87 \pm 1.16 \%$ at $0.6 \mathrm{mg} / \mathrm{mL}, 13.99 \pm 0.49 \%$ and $11.39 \pm 0.66 \%$ at $0.3 \mathrm{mg} / \mathrm{mL}$ respectively). These inhibitions rates began to decrease gradually with the treatment by $C$. ericoides and increase with the use of $C$. elongatum extract but was maintained at less than $25 \%$. The maximum inhibition rate was revealed at the last day of treatment by the extracts of $B$. secundiflora $(42.9 \pm 1.75 \%$ and $35.95 \pm 0.11 \%$ at $0.6 \mathrm{mg} / \mathrm{mL}$ and $0.3 \mathrm{mg} / \mathrm{mL}$ respectively). 


\begin{tabular}{|c|c|c|c|c|c|c|c|}
\hline \multirow[b]{2}{*}{ Treatments } & \multirow[b]{2}{*}{ Concentration (mg/mL) } & \multicolumn{6}{|c|}{ Time (days) } \\
\hline & & $\mathbf{0}$ & 1 & 2 & 3 & 4 & 5 \\
\hline \multirow[t]{2}{*}{ Codium elongatum } & 0.3 & $0 \pm 0$ & $46.23 \pm 0.4^{* * *}$ & $50.18 \pm 0.24^{* * *}$ & $40.86 \pm 0.2 * * *$ & $25.09 \pm 0.04 * * *$ & $22.24 \pm 0.24 * * *$ \\
\hline & 0.6 & $0 \pm 0$ & $66.82 \pm 0.12 * * *$ & $52.69 \pm 0.24 * * *$ & $44.86 \pm 0.03 * * *$ & $31.92 \pm 0.04 * * *$ & $25.1 \pm 0.22 * * *$ \\
\hline \multirow[t]{2}{*}{ Laminaria digitata } & 0.3 & $0 \pm 0$ & $46.65 \pm 0.62 * * *$ & $33.37 \pm 3.84 * * *$ & $23.09 \pm 0.33 * * *$ & $20.24 \pm 0.38 * * *$ & $14.67 \pm 0.2 * * *$ \\
\hline & 0.6 & $0 \pm 0$ & $49.66 \pm 0.13 * * *$ & $39.53 \pm 2.61 * * *$ & $27.22 \pm 0.14 * * *$ & $21.9 \pm 0.13 * * *$ & $15.32 \pm 0.12 * * *$ \\
\hline \multirow[t]{2}{*}{ Cystosiera ericoides } & 0.3 & $0 \pm 0$ & $39.71 \pm 2.4 * * *$ & $26.23 \pm 0.54 * * *$ & $17.43 \pm 0.18^{* * *}$ & $13.32 \pm 0.13 * * *$ & $8.25 \pm 0.48 * * *$ \\
\hline & 0.6 & $0 \pm 0$ & $60.47 \pm 0.45 * * *$ & $38.49 \pm 4.27 * * *$ & $25.71 \pm 0.28 * * *$ & $20.83 \pm 0.66^{* * *}$ & $16.27 \pm 0.16^{* * *}$ \\
\hline \multirow[t]{2}{*}{ Bifurcaria tuberculata } & 0.3 & $0 \pm 0$ & $57.27 \pm 0.81 * * *$ & $51.51 \pm 1.13^{* * *}$ & $41.07 \pm 0.05 * * *$ & $31.24 \pm 0.34 * * *$ & $24.2 \pm 0.24 * * *$ \\
\hline & 0.6 & $0 \pm 0$ & $64.88 \pm 0.17 * * *$ & $52.13 \pm 1.83 * * *$ & $41.57 \pm 0.11 * * *$ & $34.08 \pm 1.18 * * *$ & $26.54 \pm 0.05^{* * *}$ \\
\hline \multirow[t]{2}{*}{ Gelidim pulchellum } & 0.3 & $0 \pm 0$ & $39.5 \pm 0.53 * * *$ & $38.03 \pm 0.61 * * *$ & $26.2 \pm 0.65^{* * *}$ & $20.83 \pm 0.22 * * *$ & $18.06 \pm 0.33 * * *$ \\
\hline & 0.6 & $0 \pm 0$ & $57.31 \pm 0.68 * * *$ & $47.57 \pm 0.28^{* * *}$ & $33.37 \pm 0.75 * * *$ & $27.77 \pm 0.08 * * *$ & $20.61 \pm 0.35 * * *$ \\
\hline \multirow{2}{*}{ Laurentia pinnatifida } & 0.3 & $0 \pm 0$ & $45.53 \pm 1.05^{* * *}$ & $29.85 \pm 5.02 * * *$ & $22.79 \pm 0.59 * * *$ & $14.53 \pm 0.3 * * *$ & $10.01 \pm 0.19^{* * *}$ \\
\hline & 0.6 & $0 \pm 0$ & $49.46 \pm 0.52 * * *$ & $38.49 \pm 0.24 * * *$ & $34.4 \pm 1.42 * * *$ & $20.76 \pm 0.13 * * *$ & $15.03 \pm 0.23 * * *$ \\
\hline \multirow[t]{2}{*}{ Cystosiera tamarisafolia } & 0.3 & $0 \pm 0$ & $30.03 \pm 1.81 * * *$ & $34.16 \pm 1.4 * * *$ & $31.08 \pm 0.22 * * *$ & $22.03 \pm 0.5^{* * *}$ & $14.06 \pm 0.16^{* * *}$ \\
\hline & 0.6 & $0 \pm 0$ & $31.43 \pm 0.96^{* * *}$ & $36.84 \pm 0.39 * * *$ & $32.99 \pm 0.09 * * *$ & $24.24 \pm 0.28 * * *$ & $23.51 \pm 0.14 * * *$ \\
\hline \multirow[t]{2}{*}{ Halopytis incurvus } & 0.3 & $0 \pm 0$ & $39.32 \pm 0.35 * * *$ & $39.42 \pm 3.28^{* * *}$ & $26.23 \pm 0.15 * * *$ & $21.17 \pm 0.16^{* * *}$ & $11.78 \pm 0.23 * * *$ \\
\hline & 0.6 & $0 \pm 0$ & $44.5 \pm 1.26 * * *$ & $38.07 \pm 1.87 * * *$ & $27.99 \pm 0.29 * * *$ & $22.24 \pm 0.16^{* * *}$ & $15.12 \pm 0.05^{* * *}$ \\
\hline \multirow[t]{2}{*}{ Plocamium coccineum } & 0.3 & $0 \pm 0$ & $48.09 \pm 0.09 * * *$ & $40.32 \pm 2.17 * * *$ & $29.53 \pm 0.66^{* * *}$ & $21.72 \pm 0.17 * * *$ & $16.48 \pm 0.12 * * *$ \\
\hline & 0.6 & $0 \pm 0$ & $47.81 \pm 0.64 * * *$ & $54.02 \pm 2.24 * * *$ & $46.22 \pm 0.47 * * *$ & $33.56 \pm 0.14 * * *$ & $26.57 \pm 0.41 * * *$ \\
\hline \multirow[t]{2}{*}{ Ulva lactuca } & 0.3 & $0 \pm 0$ & $47.41 \pm 1.06^{* * *}$ & $42.31 \pm 2.3 * * *$ & $31.19 \pm 0.32 * * *$ & $22.32 \pm 0.13 * * *$ & $13.27 \pm 0.24 * * *$ \\
\hline & 0.6 & $0 \pm 0$ & $55.64 \pm 1.55^{* * *}$ & $53 \pm 0.49 * * *$ & $37.16 \pm 0.48 * * *$ & $28.62 \pm 0.22 * * *$ & $19.79 \pm 0.36^{* * *}$ \\
\hline \multirow[t]{2}{*}{ Rhodymenia pseudopalmata } & 0.3 & $0 \pm 0$ & $44.32 \pm 0.86^{* * *}$ & $31.08 \pm 1.43 * * *$ & $26.11 \pm 0.38^{* * *}$ & $15.43 \pm 0.1 * * *$ & $10.9 \pm 1.94 * * *$ \\
\hline & 0.6 & $0 \pm 0$ & $41.94 \pm 1.62 * * *$ & $37.47 \pm 0.08 * * *$ & $28.32 \pm 0.28 * * *$ & $21.19 \pm 0.4 * * *$ & $14.96 \pm 0.27 * * *$ \\
\hline \multirow[t]{2}{*}{ Bornetia secundiflora } & 0.3 & $0 \pm 0$ & $73.63 \pm 0.19 * * *$ & $60.72 \pm 2.44 * * *$ & $39.49 \pm 0.58 * * *$ & $26.85 \pm 0.61 * * *$ & $21.28 \pm 0.22 * * *$ \\
\hline & 0.6 & $0 \pm 0$ & $80.65 \pm 0.23 * * *$ & $78.57 \pm 0.33^{* * *}$ & $51.98 \pm 0.88^{* * *}$ & $32.64 \pm 0.5 * * *$ & $23.25 \pm 0.26^{* * *}$ \\
\hline \multirow[t]{2}{*}{ Enteromorpha intestinalis } & 0.3 & $0 \pm 0$ & $60.55 \pm 0.51 * * *$ & $35.58 \pm 2.08^{* * *}$ & $23.09 \pm 0.2 * * *$ & $17.88 \pm 1.26^{* * *}$ & $13.12 \pm 0.24 * * *$ \\
\hline & 0.6 & $0 \pm 0$ & $67.83 \pm 1.25 * * *$ & $44.11 \pm 0.32 * * *$ & $34.36 \pm 0.41 * * *$ & $23.8 \pm 0.04 * * *$ & $17.36 \pm 0.06^{* * *}$ \\
\hline \multirow[t]{2}{*}{ Sargassum muticum } & 0.3 & $0 \pm 0$ & $55.62 \pm 0.59 * * *$ & $37.88 \pm 0.84 * * *$ & $26.26 \pm 0.48^{* * *}$ & $14.81 \pm 0.43 * * *$ & $9.95 \pm 0.16 * * *$ \\
\hline & 0.6 & $0 \pm 0$ & $63.52 \pm 0.08 * * *$ & $40.29 \pm 1.11^{* * *}$ & $28.49 \pm 0.73 * * *$ & $19.83 \pm 0.59 * * *$ & $11.96 \pm 0.02 * * *$ \\
\hline \multirow{2}{*}{$\begin{array}{c}\text { Copper sulphate } \\
\text { (Positive control) }\end{array}$} & 0.3 & $0 \pm 0$ & $86.06 \pm 1.77 * * *$ & $90.54 \pm 0.27 * * *$ & $94.82 \pm 0.07 * * *$ & $95.95 \pm 0.27 * * *$ & $96.47 \pm 0.36^{* * *}$ \\
\hline & 0.6 & $0 \pm 0$ & $90.17 \pm 0.3^{* * *}$ & $96.21 \pm 0.46^{* * *}$ & $96.4 \pm 0.38 * * *$ & $97.8 \pm 0.67 * * *$ & $97.35 \pm 0.69 * * *$ \\
\hline
\end{tabular}


DMSO (Negative control) $0 \pm 0 \quad 0.48 \pm 1.1$

$0.29 \pm 1.3$

$0.11 \pm 0.53$

$0.38 \pm 0.25$

Table 2. Inhibitory rates of Moroccan seaweeds methanolic extracts on M. aeruginosa.

Each value representing mean $\pm \mathrm{SD}$ of 3 replicates, $* * * \mathrm{P}<0.001$ indicate significant differences compared with the negative control.

Table 3. Inhibitory rate of Moroccan seaweeds methanolic extracts on Chlorella sp.

\begin{tabular}{|c|c|c|c|c|c|c|c|}
\hline \multirow[b]{2}{*}{ Treatments } & \multirow[b]{2}{*}{ Concentration $(\mathrm{mg} / \mathrm{mL})$} & \multicolumn{6}{|c|}{ Time (days) } \\
\hline & & $\mathbf{0}$ & 1 & 2 & 3 & 4 & 5 \\
\hline \multirow[t]{2}{*}{ Codium elongatum } & 0.3 & $0 \pm 0$ & $11.87 \pm 1.16^{* * *}$ & $33.41 \pm 0.25 * * *$ & $32.78 \pm 0.22 * * *$ & $26.03 \pm 0.21 * * *$ & $24.72 \pm 0.12 * * *$ \\
\hline & 0.6 & $0 \pm 0$ & $11.39 \pm 0.66^{* * *}$ & $31.69 \pm 0.12 * * *$ & $31.92 \pm 0.89 * * *$ & $21.64 \pm 0.18 * * *$ & $20.17 \pm 0.26 * * *$ \\
\hline \multirow[t]{2}{*}{ Laminaria digitata } & 0.3 & $0 \pm 0$ & $11.94 \pm 0.92 * * *$ & $33.45 \pm 0.48 * * *$ & $36.28 \pm 0.38 * * *$ & $25.22 \pm 0.09 * * *$ & $24.27 \pm 0.3 * * *$ \\
\hline & 0.6 & $0 \pm 0$ & $6.87 \pm 1.34 * * *$ & $23.64 \pm 0.38 * * *$ & $21.56 \pm 0.73 * * *$ & $11.78 \pm 0.42 * * *$ & $11.43 \pm 0.25 * * *$ \\
\hline \multirow[t]{2}{*}{ Cystosiera ericoides } & 0.3 & $0 \pm 0$ & $16.64 \pm 2.81 * * *$ & $28.89 \pm 0.52 * * *$ & $24.9 \pm 1.95 * * *$ & $19.15 \pm 0.56^{* * *}$ & $12.01 \pm 0.11 * * *$ \\
\hline & 0.6 & $0 \pm 0$ & $13.99 \pm 0.49 * * *$ & $21.73 \pm 0.07 * * *$ & $19.18 \pm 0.12 * * *$ & $17 \pm 0.4 * * *$ & $14.3 \pm 0.13 * * *$ \\
\hline \multirow[t]{2}{*}{ Bifurcaria tuberculata } & 0.3 & $0 \pm 0$ & $12.68 \pm 0.33 * * *$ & $29.75 \pm 0.38 * * *$ & $33.22 \pm 0.26 * * *$ & $25.31 \pm 0.12 * * *$ & $19.86 \pm 0.17 * * *$ \\
\hline & 0.6 & $0 \pm 0$ & $-0.87 \pm 0.42 * * *$ & $17.37 \pm 0.22 * * *$ & $20.34 \pm 0.23 * * *$ & $15.59 \pm 0.27 * * *$ & $14.29 \pm 0.18 * * *$ \\
\hline \multirow[t]{2}{*}{ Gelidim pulchellum } & 0.3 & $0 \pm 0$ & $2.95 \pm 0.21$ & $16.83 \pm 0.16^{* * *}$ & $18.13 \pm 0.82 * * *$ & $16.7 \pm 0.35 * * *$ & $8.22 \pm 0.28 * * *$ \\
\hline & 0.6 & $0 \pm 0$ & $0.64 \pm 0.43 * * *$ & $13.74 \pm 0.43 * * *$ & $17.66 \pm 0.2 * * *$ & $12.68 \pm 0.18 * * *$ & $15.09 \pm 0.2 * * *$ \\
\hline \multirow[t]{2}{*}{ Laurentia pinnatifida } & 0.3 & $0 \pm 0$ & $-0.75 \pm 0.55$ & $18.33 \pm 0.24 * * *$ & $24.32 \pm 2.88 * * *$ & $21.44 \pm 0.49 * * *$ & $8.85 \pm 0.28 * * *$ \\
\hline & 0.6 & $0 \pm 0$ & $-3.12 \pm 0.5$ & $5.32 \pm 0.39 * * *$ & $11.54 \pm 0.3 * * *$ & $13.02 \pm 0.25 * * *$ & $10.35 \pm 0.35 * * *$ \\
\hline \multirow[t]{2}{*}{ Cystosiera tamarisafolia } & 0.3 & $0 \pm 0$ & $6.47 \pm 0.06$ & $37.54 \pm 6.01 * * *$ & $26.18 \pm 2.55^{* * *}$ & $20.45 \pm 9.92 * * *$ & $8.66 \pm 0.26 * * *$ \\
\hline & 0.6 & $0 \pm 0$ & $-1.88 \pm 0.27 * * *$ & $29.67 \pm 0.04 * * *$ & $19.42 \pm 0.3 * * *$ & $23.87 \pm 0.9 * * *$ & $21.33 \pm 0.11 * * *$ \\
\hline \multirow[t]{2}{*}{ Halopytis incurvus } & 0.3 & $0 \pm 0$ & $6.37 \pm 0.66$ & $36.68 \pm 0.27 * * *$ & $33.01 \pm 0.3 * * *$ & $20.47 \pm 0.56 * * *$ & $21.25 \pm 0.3^{* * *}$ \\
\hline & 0.6 & $0 \pm 0$ & $3.07 \pm 0.5^{* * *}$ & $26.15 \pm 0.36 * * *$ & $22.67 \pm 0.82 * * *$ & $18.43 \pm 0.11 * * *$ & $11.77 \pm 0.54 * * *$ \\
\hline \multirow[t]{2}{*}{ Plocamium coccineum } & 0.3 & $0 \pm 0$ & $6.75 \pm 1.04 * * *$ & $30.31 \pm 0.66^{* * *}$ & $17.16 \pm 0.52 * * *$ & $13.42 \pm 0.44 * * *$ & $2.89 \pm 0.17$ \\
\hline & 0.6 & $0 \pm 0$ & $0.23 \pm 1.28 * * *$ & $18.77 \pm 0.45 * * *$ & $22.83 \pm 1.58 * * *$ & $10.59 \pm 0.26 * * *$ & $12.45 \pm 0.1 * * *$ \\
\hline \multirow[t]{2}{*}{ Ulva lactuca } & 0.3 & $0 \pm 0$ & $4.73 \pm 0.6$ & $16.51 \pm 0.26 * * *$ & $16.07 \pm 0.27 * * *$ & $11.66 \pm 0.07 * * *$ & $10.69 \pm 0.18 * * *$ \\
\hline & 0.6 & $0 \pm 0$ & $-3.07 \pm 1.05$ & $11.95 \pm 0.19 * * *$ & $11.75 \pm 1.26^{* * *}$ & $8.53 \pm 0.17 * * *$ & $6.5 \pm 0.21 * * *$ \\
\hline \multirow[t]{2}{*}{ Rhodymenia pseudopalmata } & 0.3 & $0 \pm 0$ & $-15.94 \pm 0.19$ & $-4.47 \pm 0.63 * * *$ & $0.17 \pm 0.11$ & $1.14 \pm 0.31$ & $2.04 \pm 0.26$ \\
\hline & 0.6 & $0 \pm 0$ & $-18.87 \pm 0.38 * * *$ & $-6.08 \pm 0.26 * * *$ & $-3.53 \pm 0.27 * * *$ & $2.23 \pm 0.08 * * *$ & $2.28 \pm 0.25$ \\
\hline \multirow[t]{2}{*}{ Bornetia secundiflora } & 0.3 & $0 \pm 0$ & $6.7 \pm 0.42 * * *$ & $23.21 \pm 0.42 * * *$ & $24.28 \pm 2.07 * * *$ & $36.95 \pm 1.21 * * *$ & $42.9 \pm 1.75 * * *$ \\
\hline & 0.6 & $0 \pm 0$ & $2.89 \pm 0.72 * * *$ & $8.33 \pm 0.14 * * *$ & $18.66 \pm 0.42 * * *$ & $20.96 \pm 0.08 * * *$ & $35.95 \pm 0.11 * * *$ \\
\hline
\end{tabular}




\begin{tabular}{|c|c|c|c|c|c|c|c|}
\hline \multirow[t]{2}{*}{ Enteromorpha intestinalis } & 0.3 & $0 \pm 0$ & $2.61 \pm 0.23$ & $2.61 \pm 3.76$ & $-0.11 \pm 0.26$ & $-2.8 \pm 0.27$ & $0.39 \pm 0.26$ \\
\hline & 0.6 & $0 \pm 0$ & $-18.11 \pm 1.01 * * *$ & $3.24 \pm 1.6^{* * *}$ & $0.03 \pm 0.68$ & $-1.76 \pm 0.29$ & $-0.78 \pm 0.2$ \\
\hline \multirow[t]{2}{*}{ Sargassum muticum } & 0.3 & $0 \pm 0$ & $-6.11 \pm 0.65$ & $2.71 \pm 2.61$ & $1.72 \pm 0.06$ & $-2.2 \pm 0.32$ & $1.82 \pm 0.43$ \\
\hline & 0.6 & $0 \pm 0$ & $-2.04 \pm 0.32 * * *$ & $-2.11 \pm 2.79$ & $-2.21 \pm 0.21 * * *$ & $-5.51 \pm 0.23^{* * *}$ & $-3.12 \pm 0.31 * * *$ \\
\hline \multirow{2}{*}{$\begin{array}{l}\text { Copper sulphate } \\
\text { (Positive control) }\end{array}$} & 0.3 & $0 \pm 0$ & $35.09 \pm 0.29 * * *$ & $65.7 \pm 0.2 * * *$ & $84.56 \pm 0.07 * * *$ & $94.68 \pm 0.05 * * *$ & $95.06 \pm 0.19 * * *$ \\
\hline & 0.6 & $0 \pm 0$ & $35.09 \pm 0.29 * * *$ & $65.7 \pm 0.2 * * *$ & $84.56 \pm 0.07 * * *$ & $94.68 \pm 0.05 * * *$ & $95.06 \pm 0.19 * * *$ \\
\hline DMSO (Negative control) & & $0 \pm 0$ & $3.01 \pm 0$ & $4.28 \pm 0.9$ & $2.29 \pm 1.6$ & $-0.46 \pm 0.13$ & $-0.95 \pm 1.917$ \\
\hline
\end{tabular}

Each value representing mean $\pm \mathrm{SD}$ of 3 replicates, ${ }^{* * *} \mathrm{P}<0.001$ indicate significant differences compared with the negative control. 


\section{Effect of seaweeds methanolic extracts on growth rates of microalgae}

The experimental results expressed in growth rates $(\mu)$ of the strain M. aeruginosa and Chlorella sp. at the various macroalgal extracts treatment are shown in figure 3 and 4 . Under standard culturing conditions, the growth rates were about 0.74 /day for $M$. aeruginosa and 0.41/day for Chlorella sp., which corresponds to a generation time of $\sim 1.0$ and $\sim 2.0$ days respectively. The DMSO has no effect on the growth rates of both tested microalgae whereas copper sulphate decreased significantly the growth of $M$. aeruginosa and the culture of Chlorella died with this treatment. The results show that $\mu$ of both microalgae tests decreased significantly after treatment with the majority of the seaweed extracts tested. The extracts of $B$. tuberculata, C. elongatum and B. secundiflora have the strongest inhibitory effect on $\mu$ of tested cyanobacteria. On the other hand, the extract of $S$. muticum have no significant effect on the growth of both tested microalgae. R. pseudopalmata and E. intestinalis has no significant effect against Chlorella sp.

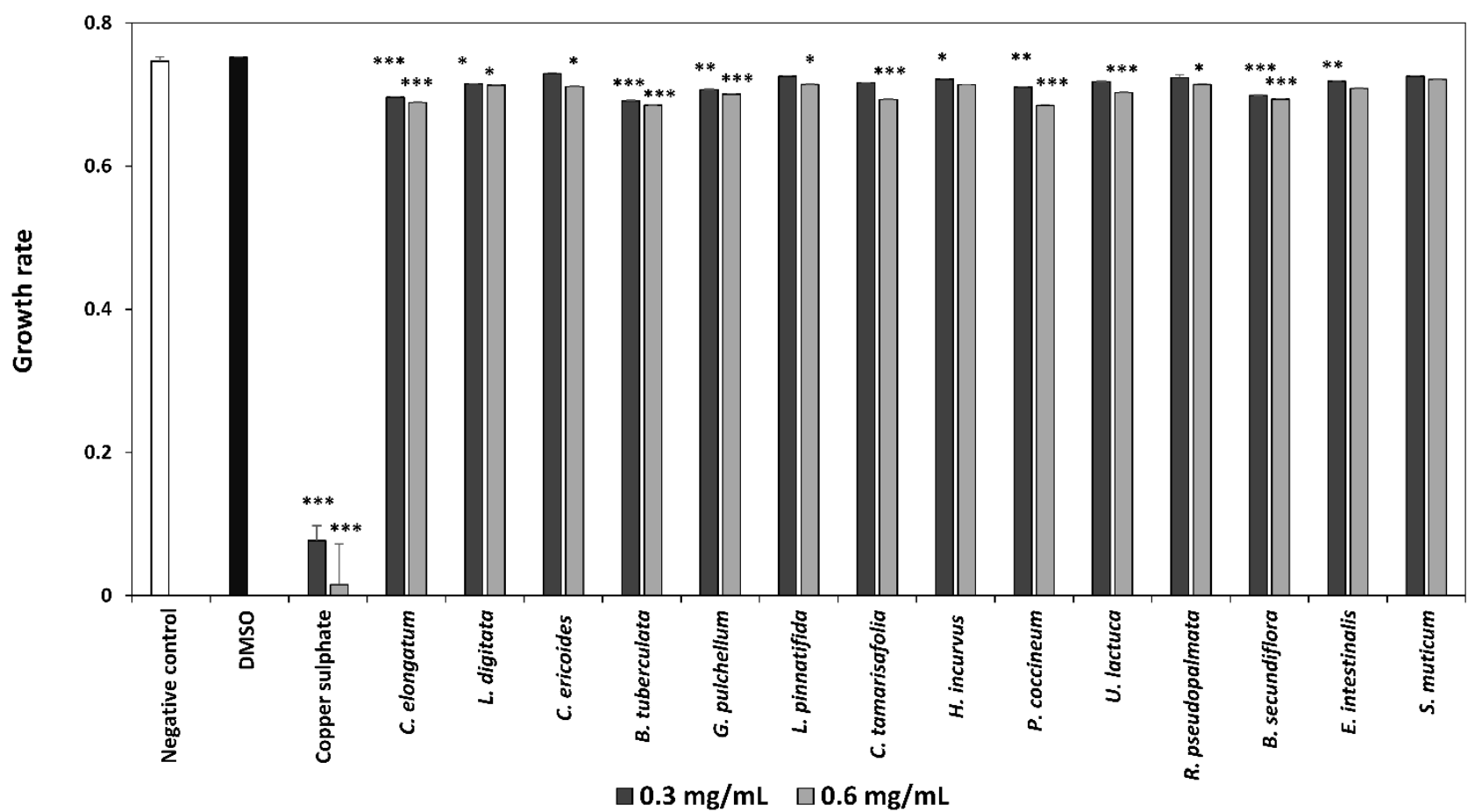

Figure 4. Effect of Moroccan seaweeds methanolic extracts on the growth rate of $M$. aeruginosa. Each value representing mean $\pm \mathrm{SD}$ of 3 replicates, ${ }^{* * *} \mathrm{P}<0.001 ; * * \mathrm{P}<0.005$ and $* \mathrm{P}<0.05$ indicate significant differences compared with the negative control. 


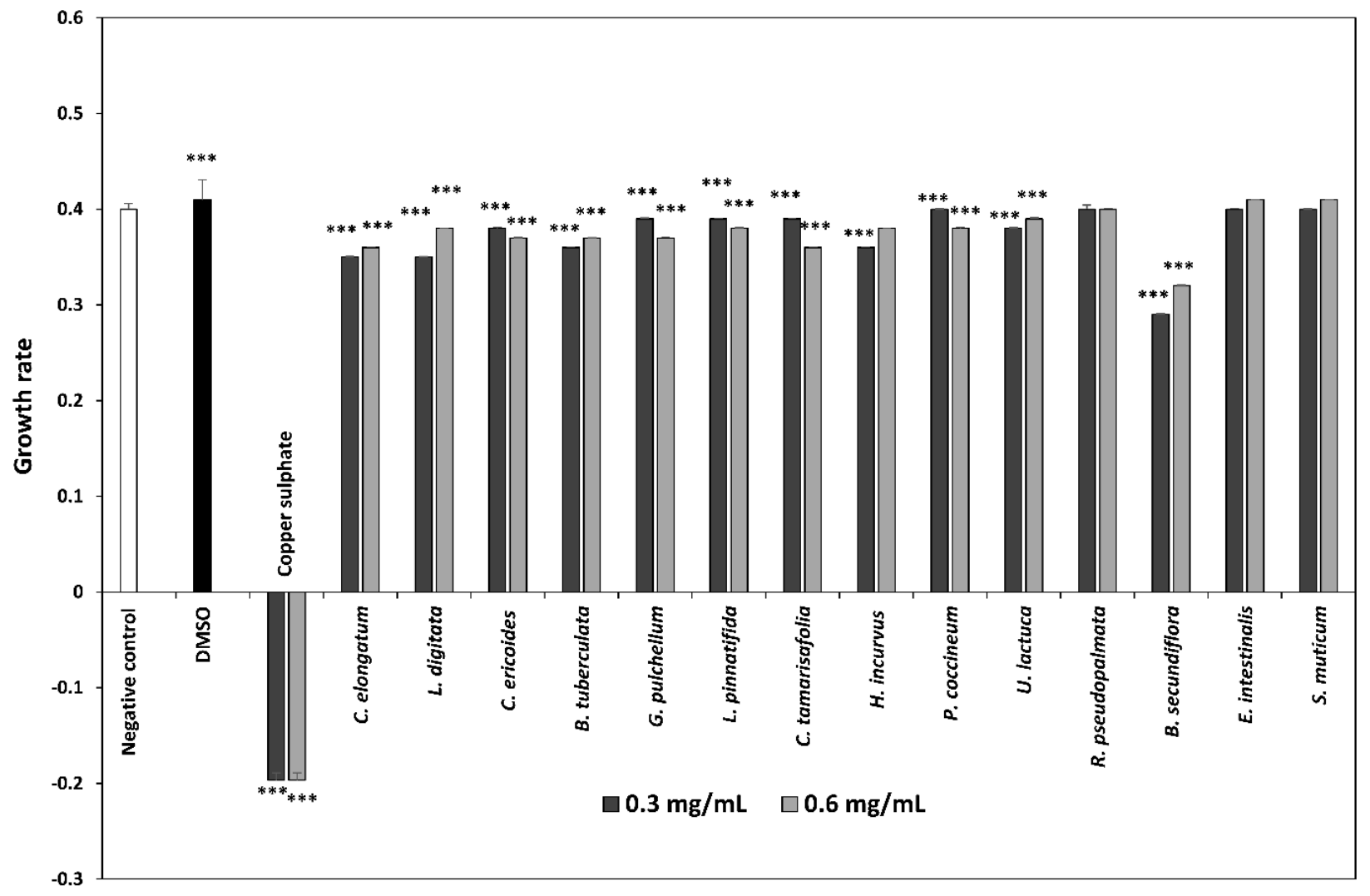

Figure 5. Effect of Moroccan seaweeds methanolic extracts on the growth rate of Chlorella sp. Each value representing mean $\pm \mathrm{SD}$ of 3 replicates, $* * * \mathrm{P}<0.001$; indicate significant differences compared with the negative control.

\section{Discussion}

This present study includes the first description of the algicidal activity in solid and liquid medium of 14 seaweeds from the coast of Morroco. In solid media the methanolic extracts of L. digitata, H. incurvus, $U$. lactuca and $S$. muticum did not show any inhibition against the Gram-negative bacteria M. aeruginosa. Whereas, Kumaresan et al. (2018) observed that aqueous extract of the genus Sargassum (S. wightii) showed a moderate antibacterial activity against gram negative bacteria $(13 \mathrm{~mm}$ against Escherichia coli and $10 \mathrm{~mm}$ against Salmonella typhi). Furthermore, Mishra (2018) reported that the methanolic extracts of $U$. lactuca and seaweed of the genus Sargassum have a moderate effect against M. aeruginosa.

In addition, we found that the methanolic extracts of $B$. secundiflora, L. pinnatifida and G. pulchellum showed a strong activity against $M$. aeruginosa $(27.33 \pm 0.33 \mathrm{~mm}, 17.33 \pm 0.33$ $\mathrm{mm}$ and $16.67 \pm 0.33 \mathrm{~mm}$, respectively). Our results are similar to those found by Al-Enazi 
et al. (2017) who investigated the antibacterial activities of three seaweeds collected from Alharra, Umluj, Kingdom of Saudi Arabia. The highest activities were obtained against the negative bacteria Klebsiella pneumonia by seaweeds of genus Laurencia (L. catarinensis) $(23.40 \pm 0.58 \mathrm{~mm})$. In another study, the methanol extract of Laurencia iliformis was the most active against $P$. aeruginosa, $S$. aureus, $S$. pyogenes and E.coli. The methanolic extract of $U$. reticulata also showed a strong effect against $P$. aeruginosa (Begum et al. 2018). Li et al. (2018) reported that the ethanolic extracts of S. fusiforme, U. pertusa and G. furcate reveal the maximum inhibitory activity against Gram-negative bacteria Escherichia coli at $10 \mathrm{mg} / \mathrm{mL}$ (10 $\mathrm{mm}, 7 \mathrm{~mm}$ and $7 \mathrm{~mm}$, respectively). Salvador et al. (2007) observed that 18 taxa of seaweeds, including E. intestinalis, Gelidium spinosum, Codium fragile, B. secundiflora, $C$. tamariscifolia, Ulva rigida did not show antimicrobial activity against any Gram negative bacteria assayed. Although, in the present study B. secundiflora, G. pulchellum and $C$. elongatum showed a strong activity against Gram-negative bacteria M. aeruginosa, $C$. tamariscifolia and E. intestinalis exhibited moderate anti-cyanobacterial activity. However, the strong algicidal activity of tested seaweeds could be explained by the presence of metabolites and natural bioactive compounds groups, such as polysaccharides, tannins, flavonoids, phenolic acids, bromophenols, and carotenoids that have been reported as bacterial inhibitors (Rodrigues et al. 2015). Pérez et al. (2016) suggested that the higher antibacterial activity of seaweeds was related to their ability to bind with bacterial proteins such as enzymes and cell membranes.

In liquid medium, all methanolic extracts of different macroalgae tested have a significant algicidal activity against the toxic cyanobacteria $M$. aeruginosa and the feed microalgae Chlorella sp. Several studies have investigated the antialgal property of seaweeds in liquid medium (Schwartz et al. 2017; Wang et al. 2018). Our results in liquid medium revealed that the extracts of $B$. tuberculata, $C$. elongatum and B. secundiflora have the strongest inhibitory effect on $\mu$ and the maximum inhibition rates of tested cyanobacteria. These results are in agreement with the observations of Zerrif et al. (2018) who reported that the methanol extract of the $C$. elongatum collected from the coast of Morocco showed a significant progressive reduction in growth of the filamentous cyanobacterium Phormidium sp. While, we found that the extract of $S$. muticum had no significant effect on the growth rate and the inhibitory rate of M. aeruginosa. Contrariwise, Renjun et al. (2012) revealed that the methanol extract of the genus Sargassum (S. thunbergii) caused a stronger inhibitory effects on the growths of red tide microalgae tests such as Heterosigma akashiwo, Skeletonema costatum and Prorocentrum micans. In another report, Sun et al. (2016b) demonstrated the algicidal 
activity of methanolic extract of Ulva prolifera in liquid medium against red tide microalgae; also, they showed that this extract has no effect on feed microalgae.

Furthermore, the decrease in growth rates of $M$. aeruginosa strain treated by the extracts of B. secundiflora, C. elongatum and B. tuberculata. compared to the control, might be explained by the presence of algicidal compounds. The potential of seaweeds as a source of active compounds against microalgae forming harmful blooms (HABs) has been confirmed in different studies. Recently, Sun et al. (2018) indicated that three sesquiterpenoids (gossonorol, 7,10-epoxy-ar-bisabol-11-ol and cyclonerodiol) had selective antialgal activity against the growth of different red tide microalgae such us Amphidinium carterae, H. akashiwo, Karenia mikimitoi, and Phaeocystis globosa. (6E,9E,12E)-(2-acetoxy- $\beta$-D-glucose)-octadecatrienoic acid ester isolated from Ulva intestinalis displayed strong algicidal activity with IC50 values of 4.9 and $14.1 \mu \mathrm{g} / \mathrm{mL}$ for H. akashiwo and P. micans, respectively (Sun et al. 2016a).

\section{Conclusion}

After screening of 14 Moroccan seaweeds species for their algicidal activity, our results revealed that seaweeds are potential producers of anti-algicidal compounds. For that reason, they should be thoroughly investigated as natural sources of bioactive substances. In order to understand the potential inhibitory effect of these seaweeds extracts, characterization of the extracts and study of the effective compounds would be the next step of our work. Moreover, further researches will need to be conducted against other seaweeds and/or phytoplankton in macrocosms and natural field conditions, with a focus on the study of the nature and stability of the specific compounds and their potentially synergistic interactions in the aquatic ecosystem.

\section{Acknowledgments}

We acknowledge the projects TOXICROP (823860) funded by the H2020 program MSCA-RISE-2018 and the project VALORMAR (24517) of the 10/SI/2016 - I\&DT Empresarial - Programas Mobilizadores, funded by the European Regional Development Fund (ERDF) and by the European Social Fund (ESF),

\section{References}

Abdel-Latif HHA-L, Shams El-Din NG, Ibrahim HAH (2018) Antimicrobial activity of the newly recorded red alga Grateloupia doryphora collected from the Eastern Harbor, Alexandria, Egypt. J Appl Microbiol. doi: 10.1111/jam.14050 
Al-Enazi NM, Awaad AS, Zain ME, Alqasoumi SI (2017) Antimicrobial, antioxidant and anticancer activities of Laurencia catarinensis, Laurencia majuscula and Padina pavonica extracts. Saudi Pharm J 26:44-52. doi: 10.1016/j.jsps.2017.11.001

An Z, Wang Z, Li F, et al (2008) Allelopathic inhibition on red tide microalgae Skeletonema costatum by five macroalgal extracts. Front Environ Sci Eng China 2:297-305. doi: $10.1007 / \mathrm{s} 11783-008-0055-3$

Begum S, Nyandoro S, Buriyo A, et al (2018) Bioactivities of extracts, debromolaurinterol And fucosterol from macroalgae species. Tanzania J Sci 44:104-116

Catherine Q, Susanna W, Isidora ES, et al (2013) A review of current knowledge on toxic benthic freshwater cyanobacteria - Ecology, toxin production and risk management. Water Res 47:5464-5479. doi: 10.1016/j.watres.2013.06.042

Chiang I-Z, Huang W-Y, Wu J-T (2004) allelochemicals of Botryococcus braunii (chlorophyceae). J Phycol 40:474-480. doi: 10.1111/j.1529-8817.2004.03096.x

Demeke A (2016) Cyanobacteria blooms and biological control Methods. 3:32-38

Gao L, Xie L (2011) Analysis of the influence of meteorological condition on cyanobacterial bloom and treatment methods in Taihu Lake. China Resour 29:35-38

Jeong JH, Jin HJ, Sohn CH, et al (2000) Algicidal activity of the seaweed Corallina pilulifera against red tide microalgae. J Appl Phycol 12:37-43. doi: 10.1023/A:1008139129057

Kamaya Y, Kurogi Y, Suzuki K (2003) Acute toxicity of fatty acids to the freshwater green alga Selenastrum capricornutum. Environ Toxicol 18:289-294. doi: 10.1002/tox.10127

Kazir M, Abuhassira Y, Robin A, et al (2019) Extraction of proteins from two marine macroalgae, Ulva sp. and Gracilaria sp., for food application, and evaluating digestibility, amino acid composition and antioxidant properties of the protein concentrates. Food Hydrocoll 87:194-203. doi: 10.1016/j.foodhyd.2018.07.047

Kumaresan M, Vijai Anand K, Govindaraju K, et al (2018) Seaweed Sargassum wightii mediated preparation of zirconia $(\mathrm{ZrO} 2)$ nanoparticles and their antibacterial activity against gram positive and gram negative bacteria. Microb Pathog 124:311-315. doi: 10.1016/j.micpath.2018.08.060

Lezcano V, Fernández C, Parodi ER, Morelli S (2018) Antitumor and antioxidant activity of the freshwater macroalga Cladophora surera. J Appl Phycol

Li F, Hu H (2005) Isolation and Characterization of a Novel Antialgal Allelochemical from Phragmites communis. Society 71:6545-6553. doi: 10.1128/AEM.71.11.6545

Li Y, Sun S, Pu X, et al (2018) Evaluation of Antimicrobial Activities of Seaweed Resources from Zhejiang Coast, China. Sustainability 10:2158. doi: 10.3390/su10072158

Meepagala KM, Schrader KK, Wedge DE, Duke SO (2005) Algicidal and antifungal compounds from the roots of Ruta graveolens and synthesis of their analogs. Phytochemistry 66:2689-2695. doi: 10.1016/j.phytochem.2005.09.019

Mishra AK (2018) Sargassum, Gracilaria and Ulva Exhibit Positive Antimicrobial Activity against Human Pathogens. OALib 05:1-11. doi: 10.4236/oalib.1104258 
Park MH, Chung IM, Ahmad A, et al (2009) Growth inhibition of unicellular and colonial Microcystis strains (Cyanophyceae) by compounds isolated from rice (Oryza sativa) hulls. Aquat Bot 90:309-314. doi: 10.1016/j.aquabot.2008.11.007

Pérez MJ, Falqué E, Domínguez H (2016) Antimicrobial action of compounds from marine seaweed. Mar Drugs 14:1-38. doi: 10.3390/md14030052

Renjun W, You W, Xuexi T (2012) Identi fi cation of the toxic compounds produced by Sargassum thunbergii to red tide microalgae . 30:778-785

Rodrigues D, Freitas AC, Pereira L, et al (2015) Chemical composition of red, brown and green macroalgae from Buarcos bay in Central West Coast of Portugal. Food Chem 183:197-207. doi: 10.1016/j.foodchem.2015.03.057

Sahnouni F, Benattouche Z, Matallah-Boutiba A, et al (2016) Antimicrobial activity of two marine algae Ulva rigida and Ulva intestinalis collected from Arzew gulf ( Western Algeria ). J Appl Environ Biol Sci 6:242-248

Salvador N, Garreta AG, Lavelli L, Ribera MA (2007) Antimicrobial activity of Iberian macroalgae. Sci Mar 71:101-113. doi: 10.3989/scimar.2007.71n1101

Sbiyyaa B, Loudiki M, Oudra B (1998) Capacité de stockage intracellulaire de l'azote et du phosphore chez Microcystis aeruginosa Kütz. Et Synechocystis sp.: cyanobactéries toxiques occa-sionnant des. Ann Limnol 34:247-257

Schrader KK (2003) Natural algicides for the control of cyanobacterial-related off-flavor in catfish aquaculture. Off-Flavors Aquac 848:195-208. doi: 10.1021/bk-2003-0848.ch014

Schwartz N, Dobretsov S, Rohde S, Schupp PJ (2017) Comparison of antifouling properties of native and invasive Sargassum (Fucales, Phaeophyceae) species. Eur J Phycol 52:116-131. doi: 10.1080/09670262.2016.1231345

Seder-Colomina M, Burgos A, Maldonado J, et al (2013) The effect of copper on different phototrophic microorganisms determined in vivo and at cellular level by confocal laser microscopy. Ecotoxicology 22:199-205. doi: 10.1007/s10646-012-1014-0

Shirai M, Matumaru K, Ohotake a, et al (1989) Development of a solid medium for growth and isolation of axenic Microcystis strains (cyanobacteria). Appl Environ Microbiol 55:2569-2571

Soliman AS, Ahmed AY, Abdel-Ghafour SE, et al (2018) Antifungal bio-efficacy of the red algae Gracilaria confervoides extracts against three pathogenic fungi of cucumber plant. Middle East J Appl Sci 08:727-735

Sun X, Jin H, Zhang L, et al (2016a) Screening and isolation of the algicidal compounds from marine green alga Ulva intestinalis. Chinese J Oceanol Limnol 34:781-788. doi: $10.1007 / \mathrm{s} 00343-016-4383-\mathrm{z}$

Sun Y ying, Meng K, Su Z xia, et al (2017) Isolation and purification of antialgal compounds from the red alga Gracilaria lemaneiformis for activity against common harmful red tide microalgae. Environ Sci Pollut Res 24:4964-4972. doi: 10.1007/s11356-016-8256-y

Sun Y ying, Wang H, Guo G lin, et al (2016b) Isolation, purification, and identification of antialgal substances in green alga Ulva prolifera for antialgal activity against the common harmful red tide microalgae. Environ Sci Pollut Res 23:1449-1459. doi: 
Sun Y ying, Zhou W jing, Wang H, et al (2018) Antialgal compounds with antialgal activity against the common red tide microalgae from a green algae Ulva pertusa. Ecotoxicol Environ Saf 157:61-66. doi: 10.1016/j.ecoenv.2018.03.051

Tazart Z, Douma M, Tebaa L, Loudiki M (2018) Use of macrophytes allelopathy in the biocontrol of harmful Microcystis aeruginosa blooms. Water Sci Technol Water Supply ws2018072. doi: 10.2166/ws.2018.072

Tebaa L, Douma M, Tazart Z, et al (2018) Assessment of the potentially algicidal effects of Thymus satureioides Coss. and Artemisia herba alba L. against Microcystis aeruginosa. Appl Ecol Environ Res 16:903-912. doi: 10.15666/aeer/1601_903912

Visser PM, Ibelings BW, Mur LR, Walsby AE (2005) The Ecophysiology of the Harmful Cyanobacterium Microcystis. Harmful Cyanobacteria 3:109-142. doi: 10.1007/1-40203022-3 6

Wang H, Liang F, Zhang L (2015) Composition and anti-cyanobacterial activity of essential oils from six different submerged macrophytes. Polish J Environ Stud 24:333-338. doi: $10.15244 /$ pjoes $/ 26383$

Wang R, Chen J, Ding N, et al (2018) Antialgal effects of $\alpha$-linolenic acid on harmful bloomforming Prorocentrum donghaiense and the antialgal mechanisms. Environ Sci Pollut Res 1-9. doi: 10.1007/s11356-018-2536-7

Wu ZB, Zhang SH, Wu XH, et al (2007) Allelopathic interactions between Potamogelon maackianus and Microcystis aeruginosa. Allelopath J 20:327-338

Xu H, Paerl HW, Qin BQ, et al (2010) Nitrogen and phosphorus inputs control phytoplankton growth in eutrophic Lake Taihu, China. Limnol Oceanogr 55:420-432. doi: 10.4319/lo.2010.55.1.0420

Zerrif SEA, El Ghazi N, Douma M, et al (2018) Potential uses of seaweed bioactive compounds forharmful microalgae blooms control : Algicidal effects and algal growth inhibition of Phormidium sp ( freshwater toxic cyanobacteria ). Smetox J 1:59-62

Zerrifi SEA, Khalloufi F El, Oudra B, Vasconcelos V (2018) Seaweed bioactive compounds against pathogens and microalgae: Potential uses on pharmacology and harmful algae bloom control. Mar Drugs 16:. doi: 10.3390/md16020055

Zhu J, Liu B, Wang J, et al (2010) Study on the mechanism of allelopathic influence on cyanobacteria and chlorophytes by submerged macrophyte (Myriophyllum spicatum) and its secretion. Aquat Toxicol 98:196-203. doi: 10.1016/j.aquatox.2010.02.011 